\title{
Paclitaxel Based CCRT Is an Acceptable Alternative for Cisplatin Based CCRT in the Treatment of Locally Advanced (Stage IVA) Head Neck Carcinoma
}

\author{
Md. Zillur Rahman Bhuiyan, ${ }^{1, ~ *, ~ R o k a y a ~ S u l t a n a ~}{ }^{1}$, Ranjan Kumar Bhoumic ${ }^{2}$, \\ Sayed Farhan Ali Razib ${ }^{3}$, Ashish Kumar Shaha ${ }^{4}$, Ariful Haque ${ }^{4}$ \\ ${ }^{1}$ Department of Clinical Oncology, Bangabandhu Sheikh Mujib Medical University, Dhaka, Bangladesh \\ ${ }^{2}$ Department of Radiotherapy, National Institute of Cancer Research and Hospital, Dhaka, Bangladesh \\ ${ }^{3}$ Department of Head Neck Oncology, Bangabandhu Sheikh Mujib Medical University, Dhaka, Bangladesh \\ ${ }^{4}$ Department of Radiotherapy, Dhaka Medical College Hospital, Dhaka, Bangladesh
}

Email address:

mdfaisal.bgt@gmail.com (Md. Z. R. Bhuiyan)

${ }^{*}$ Corresponding author

\section{To cite this article:}

Md. Zillur Rahman Bhuiyan, Rokaya Sultana, Ranjan Kumar Bhoumic, Sayed Farhan Ali Razib, Ashish Kumar Shaha, Ariful Haque. Paclitaxel Based CCRT Is an Acceptable Alternative for Cisplatin Based CCRT in the Treatment of Locally Advanced (Stage IVA) Head Neck Carcinoma. Cancer Research Journal. Vol. 9, No. 3, 2021, pp. 166-170. doi: 10.11648/j.crj.20210903.16

Received: August 3, 2021; Accepted: August 12, 2021; Published: August 24, 2021

\begin{abstract}
Introduction: Head neck carcinoma is the sixth most common cancer in the world. Concurrent chemo radiation became standard protocol for patients with locally advanced squamous cell carcinoma of head neck where curable surgery is not feasible. Study Design and Objective: This quasiexperimental study done to compare the treatment response and acute toxicities with the treatment of low dose weekly Paclitaxel with radiation versus weekly Cisplatin with radiation therapy for histologically proven Stage- IVA squamous cell carcinoma of head neck. Methods: All the patients were divided in two groups. Arm-A, 45 number patients received injection Paclitaxel $40 \mathrm{mg} / \mathrm{m}^{2}, \mathrm{i} / \mathrm{v}$ in $1 \mathrm{hr}$. infusion weekly for 6 weeks and in Arm- B, 45 number patients received injection Cisplatin $30 \mathrm{mg} / \mathrm{m}^{2}, \mathrm{i} / \mathrm{v}$ in $2 \mathrm{hrs}$ infusion weekly for 6 weeks. All patients received 66 Gray (Gy) radiation at the rate of $2 \mathrm{~Gy} / \mathrm{day}, 5$ fractions in a week for 6.5 weeks. Results: In this study about $65.55 \%$ patients were smoker. Most common sub site was larynx $(41.46 \%)$ followed by oral cavity $(25.00 \%)$ The most common presenting features were cervical lymphadenopathy (100.00\%) followed by pain (70.00\%), sore throat $(43.33 \%)$ and hoarseness of voice $(41.11 \%)$. Complete response showed in the patients of Arm-A, $73.33 \%$ among the smoker and $66.67 \%$ in non-smoker, whereas $72.41 \%$ in smoker and $62.50 \%$ in non-smoker showed complete response in the patients of Arm-B. Common toxicities related to treatment were mucosities, skin reaction, vomiting, nausea, weight loss, anaemia, leucopcnia, thrombocytopenia and diarrhoea. The toxicities in Arm-A were more than that of Arm-B, but were manageable. Conclusion: In this study it is evident, the concurrent chemo radiotherapy with weekly Paclitaxel is suitable alternative when Cisplatin cannot be given safely.
\end{abstract}

Keywords: Paclitaxel, Cisplatin: (Anti Cancer Drugs), Gy (Gray): Radiation Unit, CCRT: (Concurrent Chemoradiotherapy:), Locally Advanced Head Neck Carcinoma

\section{Introduction}

Head neck carcinoma is the sixth most common cancer in the world. Worldwide, approximately 600,000 patients are histopathologically detected. Nearly $60 \%$ of this population present with locally advanced but non metastatic disease [7]. Head Neck cancer is more common in men. $66 \%$ to $95 \%$ of cases occur in men. The incidence of head and neck cancer increases with age, especially after 50 years of age. Although most patients arc between 50 and 70 years age, younger patients can also develop head and neck cancer [8]. The usual time of diagnosis is after the age of 40, except for salivary gland and nasopharyngeal cancers which may occur in younger age group [8].

The higher incidence of the disease in Bangladesh thought 
to reflect the prevalence of risk factors, such as betel nut chewing and use of smokeless tobacco [3]. In united states, the higher incidence among urban males in thought to reflect exposure to tobacco and alcohol. Risk factors for head and neck cancer include tobacco and alcohol use, ultraviolet light exposure, viral infection and environmental exposures [7]. Human Papillomavirus infection (HPV; most commonly HPV-16) plays a role in the development of certain head and neck cancers, particularly those in the oropharynx 65 More than $90 \%$ of malignancies are of squamous cell histology [5, 9]. Cancers of the CNS, the eye, the esophagus, and the thyroid gland, as well as those of the scalp, skin, muscles, and bones of the head and neck, are not usually classified as head and neck cancers. Head Neck cancers encompass a diverse group that are oral cavity, oropharynx, larynx, nasopharynx, hypopharynx, paranasal sinuses, salivary glands and ear. Although the treatment for these area is often highly specialized, they also have many features is common with regard to investigation, diagnosis and management.

Head neck cancers staging is complex and depends on the anatomic location of the tumor for practical purposes [1]. Head neck cancers is divided into three clinical stages: early, locoregionally advanced, and recurrent or metastatic. Treatment approaches can vary depending on the disease stage. The majority of patients present with locoregionally advanced disease. Sometimes the advanced disease (stage-IVA) would not feasible for curable surgery.

The concurrent administration of chemotherapy and radiation has improved outcomes in a variety of clinical scenarios [6]. These include all but specially locally advanced nasopharyngeal carcinomas, advanced unresectable cancers, organ preservation in locally advanced larynx and base of the tongue cancers and in high-risk post operative patients. Thus, concurrent chemoradiation is accepted as a standard option for these patients $[8,10,11]$. Meta-analysis demonstrates that the addition of chemotherapy concurrent to radiation therapy results in up to a $4 \%$ to $8 \%$ absolute improvement in survival, which amounts to a $12 \%$ to $19 \%$ reduction in the risk of death, whether in definitive or post-operative adjuvant setting [2, 5].

Radiotherapy and concurrent chemotherapy represents the most commonly used strategy and is a more attractive approach because some chemotherapeutic agents may have both radiosensitize cells and provide additive cytotoxicity $[8,12]$. Cisplatin improves the anti-tumor efficacy of radiation therapy. Also taxane-based chemotherapies emerged as one of the most powerful compounds that might improve loco-regional control. Paclitaxel is one of the most active agents for squamous cell carcinoma of head neck in the metastatic and recurrent setting and has been shown to be a radiosensitizer when paclitaxel (low dose) uses concurrently with radiation for human squamous cell carcinoma of head neck cell lines. Paclitaxel has high-affinity binding to microtubules enhances tubulin polymerization. Normal dynamic process of microtubule network is inhibited, leading to inhibition of mitosis and cell division [4].

\section{Methods}

This was a quasiexperimental study with two comparison group which include low dose weekly paclitaxel with radiation in arm $\mathrm{A}$ and low dose weekly cisplatin with radiation in arm $\mathrm{B}$ to observe and compare the treatment effects, response rate and clinical outcome by two modalities of treatment planning. Patient with locally advanced squamous cell carcinoma of head neck treated with concurrent chemo radiation either by paclitaxel or cisplatin at Bangabandhu Sheikh Mujib Medical University Dhaka, National Institute of Cancer Research \& Hospital, Dhaka between June 2016 to May 2018 were enrolled in this study and were convinced to participate in the study after giving written informed consent and satisfying inclusion and exclusion criteria. In this study, total 90 patients of locally Stage-IVA squamous cell carcinoma of head and neck cancer were treated. Among them 45 patients who received Paclitaxel $40 \mathrm{mg} / \mathrm{m}^{2}$ I.V 1 hour infusion weekly for 6 weeks, (Arm A) and the rest 45 patients received Cisplatin $30 \mathrm{mg} / \mathrm{m}^{2}, \mathrm{I} . \mathrm{V} 2$ hours infusion weekly for 6 weeks (Arm B). All patients received 66 Gy concurrent radiation using a LINAC/ Tele Cobalt 60 Machine, at the rate of 2 Gy/day, 5 fractions/week, over a period of 6.5 weeks.

\section{Results}

A total number of 90 patients were enrolled in this observational study to compare the effectiveness, toxicity of low dose weekly Paclitaxel with radiation versus low dose weekly Cisplatin with radiation in the treatment of locally advance head neck cacinoma. Among 90 subjects, 45 subjects were in Arm-A, treated with concurrent chemoradiation with Paclitaxel and Arm-B 45 subjects treated with concurrent chemoradiation with Cisplatin. Subjects clinical condition was assessed. Then outcome of these two treatment techniques were studied. Following table showing the distribution of patients on the basis of different parameters/ variables.

Table 1. Distribution of the patients according to the use of Oral Tobacco and PanMasala.

\begin{tabular}{lllll}
\hline Oral tobacco and & \multicolumn{2}{l}{ Arm A } & \multicolumn{3}{l}{ Arm B } \\
\cline { 2 - 5 } pan masala use & $\mathbf{n}$ & $\mathbf{\%}$ & $\mathbf{n}$ & $\mathbf{\%}$ \\
\hline Yes & 30 & 66.67 & 29 & 64.44 \\
No & 15 & 33.33 & 16 & 35.56 \\
Total & 45 & 100.0 & 45 & 100.0 \\
\hline
\end{tabular}

No significant difference was found between these two group.

Table 2. Distribution of patients according to the site of Primary Tumour.

\begin{tabular}{llll}
\hline \multirow{2}{*}{ Site } & No. of patients & Total no. of patients \\
\cline { 2 - 4 } & Arm-A $(\mathbf{n}=\mathbf{4 5})$ & Arm-B $(\mathbf{n}=\mathbf{4 5})$ & and Percentage (N=90) \\
\hline Oral cavity & 11 & 12 & $23(25.00 \%)$ \\
Nasopharynx & 06 & 09 & $15(16.66 \%)$ \\
Oropharynx & 04 & 03 & $07(08.33 \%)$ \\
Hypopharynx & 01 & 02 & $03(03.33 \%)$ \\
Larynx & 19 & 18 & $37(41.66 \%)$ \\
Others & 04 & 01 & $05(05.00 \%)$ \\
\hline
\end{tabular}

No significant difference was found between these two group. 
Table 3. Distribution of patients by Clinical Features (before treatment).

\begin{tabular}{llll}
\hline \multirow{2}{*}{ Clinical features } & \multicolumn{2}{l}{ No. of patients } & \multirow{2}{*}{ N=90 and \%) } \\
\cline { 2 - 3 } & $\begin{array}{l}\mathbf{A r m}-\mathbf{A}(\mathbf{n}= \\
\mathbf{4 5})\end{array}$ & $\begin{array}{l}\mathbf{A r m}-\mathbf{4 5}) \\
\mathbf{4 n}=\end{array}$ & \\
\hline Cervical lymphadenopathy & 45 & 45 & $90(100 \%)$ \\
Pain & 33 & 30 & $63(70.00 \%)$ \\
Sore throat & 21 & 18 & $39(43.33 \%)$ \\
Hoarseness of voice & 21 & 16 & $37(41.11 \%)$ \\
Dysphagia & 13 & 11 & $24(26.67 \%)$ \\
Otalgia & 01 & 03 & $04(4.44 \%)$ \\
\hline
\end{tabular}

Table 4. Distribution of patients by treatment response in smoker.

\begin{tabular}{lll}
\hline Response & Arm-A Smoker n-30 & Arm-B Smoker n-29 \\
\hline Complete response number $22(73.33 \%)$ & $21(72.41 \%)$ \\
Partial response number & $08(26.67 \%)$ & $08(27.59 \%)$ \\
\hline
\end{tabular}

No significant difference was found between these two group.

Table 5. Distribution of patients by treatment response in non-smoker.

\begin{tabular}{lll}
\hline Response & $\begin{array}{l}\text { Arm-A Non } \\
\text { Smoker n-15 }\end{array}$ & $\begin{array}{l}\text { Arm-B Non Smoker } \\
\text { n-16 }\end{array}$ \\
\hline Complete response number & $10(66.67 \%)$ & $10(62.50 \%)$ \\
Partial response number & $05(33.33 \%)$ & $06(37.50 \%)$ \\
\hline
\end{tabular}

No significant difference was found between these two group.

Table 6. Distribution of the patients by Treatment Response.

\begin{tabular}{lllllll}
\hline $\begin{array}{l}\text { Status at last follow-up } \\
\text { (After 24 weeks of }\end{array}$ & \multicolumn{2}{c}{ Arm A } & \multicolumn{3}{c}{ Arm B } & \multicolumn{2}{c}{ Total } \\
\cline { 2 - 7 } & $\mathbf{N}$ & $\mathbf{\%}$ & $\mathbf{N}$ & $\mathbf{\%}$ & $\mathbf{N}$ & $\mathbf{\%}$ \\
\hline Complete response & 32 & 71.11 & 31 & 68.89 & 63 & 70 \\
Partial response & 13 & 28.89 & 14 & 31.11 & 27 & 30 \\
No response & 0 & 0 & 0 & 0 & 0 & 0 \\
Progressive disease & 0 & 0 & 0 & 0 & 0 & 0 \\
Total & 45 & 100.0 & 45 & 100.0 & 90 & 100.0 \\
\hline
\end{tabular}

Table 7. Distribution of the patients on Treatment Related Haematological and Non-Haematological Toxicities.

\begin{tabular}{lllll}
\hline \multirow{2}{*}{ Variable } & Arm-A n=45 & \multicolumn{3}{c}{ Arm-B n=45 } \\
\cline { 2 - 5 } & No. of patients & $\mathbf{( \% )}$ & No. of patients & (\%) \\
\hline Mucositis & & & & \\
Group I & 03 & 06.67 & 00 & 00.00 \\
Group II & 18 & 40.00 & 12 & 26.67 \\
Group III & 10 & 22.22 & 10 & 22.22 \\
No significant difference between these two group & \\
Skin reaction & & & \\
Group I & 12 & 26.66 & 27 & 60.00 \\
Group II & 24 & 53.33 & 10 & 22.22 \\
Group III & 09 & 20.00 & 08 & 17.78 \\
No significantdifference between these two group & \\
Vomiting & & & 22.22 \\
Group I & 01 & 02.22 & 10 & 40.00 \\
Group II & 07 & 15.58 & 18 & 08.89 \\
Group III & 03 & 06.67 & 04 & \\
\hline
\end{tabular}

No significantdifference between these two group.

\begin{tabular}{lllll}
\hline \multirow{2}{*}{ Variable } & Arm-A n=45 & \multicolumn{3}{c}{ Arm-B $\mathbf{n}=\mathbf{4 5}$} \\
\cline { 2 - 5 } & No. of patients & $\mathbf{( \% )}$ & No. of patients & $(\mathbf{\%})$ \\
\hline Nausea & & & & \\
Group 1 & 06 & 13.33 & 10 & 22.22 \\
Group 11 & 12 & 26.67 & 14 & 31.11 \\
Group 111 & 01 & 02.22 & 02 & 04.44 \\
\hline
\end{tabular}

\begin{tabular}{|c|c|c|c|c|}
\hline \multirow{2}{*}{ Variable } & \multicolumn{2}{|l|}{ Arm-A n=45 } & \multicolumn{2}{|l|}{ Arm-B n=45 } \\
\hline & No. of patients & (\%) & No. of patients & (\%) \\
\hline \multicolumn{5}{|c|}{ No significant difference between these two group } \\
\hline \multicolumn{5}{|c|}{ Weight loss } \\
\hline Group 1 & 15 & 33.33 & 09 & 20.00 \\
\hline Group 11 & 09 & 20.00 & 05 & 11.11 \\
\hline Group 111 & 00 & 00 & 01 & 02.22 \\
\hline \multicolumn{5}{|c|}{ No significant difference between these two group } \\
\hline \multicolumn{5}{|c|}{ Anaemia } \\
\hline Group 1 & 15 & 33.33 & 12 & 26.67 \\
\hline Group 11 & 05 & 11.11 & 03 & 06.67 \\
\hline Group 111 & 01 & 02.22 & 01 & 02.22 \\
\hline \multicolumn{5}{|c|}{ No significant difference between these two group } \\
\hline \multicolumn{5}{|c|}{ Leucopenia } \\
\hline Group 1 & 09 & 20.00 & 06 & 13.33 \\
\hline Group 11 & 06 & 13.33 & 05 & 11.11 \\
\hline Group 111 & 01 & 02.22 & 01 & 02.22 \\
\hline \multicolumn{5}{|c|}{ No significant difference between these two group } \\
\hline \multicolumn{5}{|l|}{ Diarrhoea } \\
\hline Group 1 & 02 & 04.44 & 03 & 06.67 \\
\hline Group 11 & 03 & 06.67 & 04 & 08.89 \\
\hline Group 111 & 01 & 02.22 & 01 & 02.22 \\
\hline
\end{tabular}

No significant difference between these two group.

\section{Discussion}

The Incidence of head and neck cancer increases with age, especially after 50 years of age. Most patients are between 50 to 70 years old. In this study the patients aged between 17 years to 69 years with a mean age of 53.4 years. This is consistent with the above statement.

Head and Neck cancer is a predominantly male disease. As regards to sex of head and neck cancer have shown male and female ratio was $5: 1,66 \%$ to $95 \%$ of case occur in men [13].

Head and neck tumors occur six times more often among cigarette smokers than non-smokers $[5,13]$. In this study, among 90 patients $59(65.55 \%)$ were found smokers, which reflects the strong association of smoking with head and neck cancer.

Pain, sore throat and hoarseness of voice are the cardinal presenting symptoms of head and neck cancer. In this study, among the 90 cases $63(70 \%)$ cases presented with pain, 39 $(43.33 \%)$ cases presented with sore throat and $37(41.11 \%)$ cases presented with hoarseness of voice. All the patients $(100 \%)$ of this study presented with cervical lymphadenopathy. As only locally advanced head and neck cancer cases were taken as study population.

Multimodality therapy is required for management of locally advanced head and neck cancer (Stage-IVA). Currently four multimodality treatment approaches are used. They are concurrent chemo radiation. Induction chemotherapy followed by radiotherapy. Radiotherapy alone and surgery followed by adjuvent concurrent chemo radiotherapy.

Concurrent chemo radiotherapy is the standard care for patients with potentially unresectable locally advanced squamous cell carcinoma of head and neck cancer [12]. The optimal chemotherapy agents and their dose schedules have yet to be defined. Cisplatin improves the anti-tumour efficacy of radiation therapy with 5 -year loco-regional control rates between $35-70 \%$. The last decade witnessed the introduction 
of new chemotherapeutic agents, among these, taxane-based chemotherapies emerged as one of the most powerful compounds that might improve loco-regional control [10]. The aim of this study was to compare the outcome and toxicity of weekly Paclitaxel with weekly Cisplatin-bascd concurrent chemoradiation in locally advanced squamous cell carcinoma of head and neck cancer.

Patients were evaluated weekly by history, physical examination and laboratory investigation during treatment period. The response evaluation was performed 6 weeks after the completion of concurrent chemo radiotherapy and every 6 weeks thereafter for six months.. For the evaluation of tumor response, physical examination, radiologically image and panendoscopy when it was indicated, were performed, as well as CT and/or MRI for objective evaluation. The primary end point of our study was response rate. For the evaluation of the response to concurrent chemoradiotherapy, tumour response criteria of the World Health Organization (WHO) was applied [13].

In this study, total 90 patients of locally advanced (StageIVA) squamous cell carcinoma of head and neck cancer were treated. Among them 45 patients who received Paclitaxel 40 $\mathrm{mg} / \mathrm{m}^{2} \mathrm{I} . \mathrm{V} 1$ hour infusion weekly for 6 weeks, (Arm A) and the rest 45 patients received Cisplatin $30 \mathrm{mg} / \mathrm{m}^{2}$, I.V 2 hours infusion weekly for 6 weeks (Arm B). All patients received 66 Gy concurrent radiation using a LINAC/Tele Cobalt 60 Machine, at the rate of 2 Gy/day, 5 fractions/week, over a period of 6.5 weeks (6). Complete response was achieved in $71.11 \%$ cases of Arm-A where only $68.89 \%$ of cases of Arm-B showed complete response.

While partial response was achieved in $28.89 \%$ in Arm-A and $31.11 \%$ in Arm-B. Thus, the objective overall response was with no statistically significant difference. So, the results of weekly Paclitaxel schedule in the treatment of locally advanced squamous cell carcinoma of head and neck cancer were comparable to those of weekly Cisplatin schedule with no additional efficacy.

Toxicities were evaluated by history, physical examination and laboratory blood cell counts and scrum tests. Laboratory and clinical toxicities were considered acute if discovered during the first 12 weeks after the initiation of therapy. The grading system was based on the Radiation Therapy Oncology Group (RTOG), acute radiation morbidity scoring criteria for the following in-field toxicities $[4,5,8]$.

Mucositis, nausea and skin reaction were the common treatment related toxicities in both arms. The patients of Arm-A, suffered from vomiting less often $(24.44 \%)$ than that of Arm-B (58.18\%). Other toxicities like weight loss and hacmatological toxicities (anaemia, leucopenia) were more common in Arm-A. All the toxicities were managed effectively by conservative management.

Survival in head and neck cancers depends on treatment response and locoregional control of the disease. Recent studies have demonstrated that concurrent chemo radiation is superior in head and neck malignancies regarding local tumor control and perhaps overall survival.

\section{Conclusion}

In this study it is evident, the clinical response and toxicities produced by weekly low dose paclitaxel with radiation in the treatment of locally advanced (Stage-IVA) squamous cell carcinoma of head and neck cancer were comparable to those of weekly Cisplalin with radiation showed almost same efficacy. So, concurrent chemo radiotherapy with weekly Paclitaxel is feasible when Cisplatin can not be given safely. This study done with the limitations of smaller sample size and conducted in two centre only which does not represent the picture of the whole country.

\section{Limitations of the Study}

This study done with the limitations of smaller sample size and conducted in two centre only which does not represent the picture of the whole country.

\section{Conflict of Interest}

Authors declered no conflict of interest.

\section{References}

[1] AJCC Cancer Staging Manual. $7^{\text {th }}$ edition. New York, NY: Spingcr- Vcrlag, 2010

[2] Bomford CK, Kunkler IH, Sherrif SB. Miller Text Book of Radiotherapy, Radiation Physics, Therapy and Oncology, 6, $\mathrm{h}$ edition, Edinburgh Churchill Livingstone, 2003; pp $355-70$.

[3] Cancer Registry Report 2008-2010, Distribution of patients by systemic diagnosis. Cancer Registry Report, National Institute of Cancer Research and Hospital, Mohakhali. Dhaka, pp 10-18.

[4] Chu E, DeVitaJr VT. Physicians' Cancer Chemotherapy Drug Manual 2013, 13th edition, Jones \& Bartlett learning. LLC. an Ascend Learning Company, 2013; pp 303-307.

[5] DevitaJr VT. Lawrence TS, Rosenberg SA. Cancer Principles \& Practice of Oncology, $10^{\text {th }}$ edition, Lippincot Williams \& Wilkins. 2015; pp 424-464.

[6] Dobbs J, Banett A. Ash D. Practical radiotherapy Planning. $4^{\text {th }}$ edition, UK, 2009; 88-94.

[7] GLOBOCAN database. 2012., International agency for research on cancer, WHO. Cancer Incidence and Mortality $<\mathrm{http} / / /$ globocan.iarc.fr>

[8] Halperin EC, Perez CA, Brady LW. Perez and Brady's Principles and Practice of Oncology, $6^{\text {th }}$ edition, Lippincot Williams \& Wilkins, 2013; 718-729.

[9] Pazdur R, Wagman LD, Camhausen KA, Hoskins WJ. Cancer Management: A Multidisciplinary' Approach, 13th edition, UBM Medica LLC, New York, 2010.

[10] Perri F, Integrated therapeutic approaches in head neck cancer: the importance of multidisciplinary team management Anticancer Agents Med. Chem. 2013; 13: 834-43. 
[11] RTOG 0417, this protocol was designed and developed by the Radiation Therapy Oncology Group (RTOG) of the American College of Radiology (ACR).

[12] Symonds P, Deehan C, Mills JA, Meredith C. Walter and Miller's Textbook of Radiotherapy, 7th edition. Churchil Livingstone, London. 2012; pp 341-380.
[13] WHO. 2002. National Cancer Control Programmes: Policies and managerial guidelines. 2nd ed. Geneva: World Health Organization. 